\title{
Development and experimental validation of a numerical model for the prediction of ground vibration generated by pavement breaking
}

\author{
M.A. Lak*, S. François, G. Degrande, G. Lombaert** \\ Department of Civil Engineering, KU Leuven, Kasteelpark Arenberg 40, B-3001 Leuven, Belgium
}

\begin{abstract}
Pavement breakers are used to break rigid pavements and obtain a suitable foundation for new top layers or to enable pavement removal. The operation of falling weight pavement breakers generates high levels of ground vibration which is potentially damaging to nearby buildings and infrastructure. A numerical model for the prediction of ground vibration generated by pavement breaking is presented in this paper. First, the impact load due to a single blow of a falling weight pavement breaker is estimated by means of a simplified model of the hammer, the pavement, and the underlying soil. The predicted impact load is in good agreement with experimental results, which have been estimated from measured accelerations of one of the hammers of a pavement breaker. Second, the response of the pavement and the soil due to the impact load is considered. In order to account for inelastic soil behaviour and slab uplifting, a non-linear model of the coupled road-soil system is developed. Predictions of ground vibrations generated by the operation of a multi-head pavement breaker are validated by comparison with experimental results. A relatively good agreement is obtained between the results of the non-linear model and measured ground vibration. Comparison with results obtained with a linear model shows that disregarding non-linear phenomena leads to significant overestimation of the ground vibration levels close to the source, whereas similar results are obtained at larger distances.
\end{abstract}

Keywords: pavement breaking, ground vibration, falling weight impact, non-linear dynamic soil-structure interaction, construction induced vibration

\section{Introduction}

Pavement breaking is commonly performed to enable the removal of rigid pavements or as a first step in road rehabilitation before pavement overlay. One of the main concerns in the operation of falling weight pavement breakers is the high level of ground vibration generated by the impacts of the drop hammers. Close to the location of operation, the peak particle velocity (PPV) in the soil can exceed $5 \mathrm{~mm} / \mathrm{s}$ which is considered as the lower limit for architectural damage. For this reason, pavement breaking is considered as one of the most important anthropogenic vibration sources [1], together with pile driving, demolition activities, and blasting [2].

The fear for damage to buildings and underground infrastructure such as pipelines [3] prohibits the employment of pavement breakers in many practical situations. In order to better understand and control the risks involved, a good estimate of ground vibration levels is crucial. Up to now, such estimations are mainly based on empirical data and therefore limited to the type of equipment, pavement, and soil for which data are available. Within the frame of the present paper, a numerical model is presented which allows for predictions for a wider range of parameters. The model is validated by comparison with measurements which have been performed along the N9 motorway in Waarschoot (Belgium), where a multi-head breaker (MHB) has been used to transform the rigid pavement into a suitable foundation for a new asphalt top layer (figure 1). The acceleration of one of the drop hammers was measured simultaneously with accelerations of the concrete slab and the soil's surface at various distances from the source.

\footnotetext{
* Presently at SECO, Technical Control Bureau for Construction, Rue d'Arlon, 53 B-1040 Brussels, Belgium

** Corresponding author

Email address: geert. lombaert@bwk. kuleuven. be (G. Lombaert)

Postprint submitted to Soil Dynamics and Earthquake Engineering

Published version: M.A. Lak, S. François, G. Degrande, and G. Lombaert. Development and experimental validation of a numerical model for the prediction of ground vibration generated by pavement breaking. Soil Dynamics and Earthquake Engineering, 79:199-210, 2015. http://dx.doi.org/10.1016/j.soildyn.2015.09.015
} 


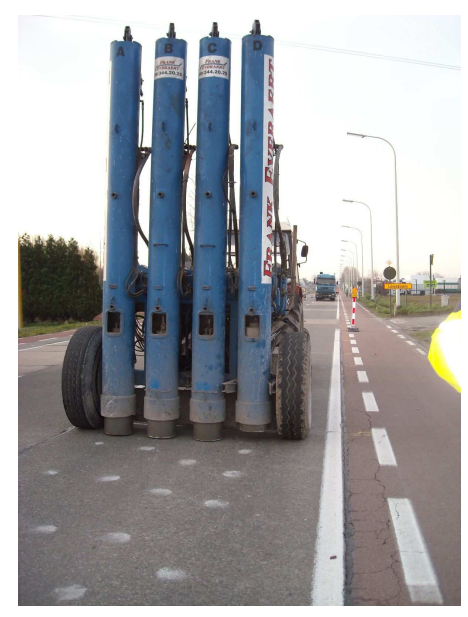

Figure 1: Multi-head pavement breaker used for fracturing of the concrete roads.

The outline of this paper is as follows. Section 2 deals with the prediction of the impact load due to a single blow of the pavement breaker. The load is predicted by means of a simplified model of the hammer, the pavement, and the underlying soil. The predicted impact load is compared to experimental results, obtained from measured acceleration of one of the hammers of the pavement breaker. In section 3, the response of the pavement and the soil is predicted and validated by comparison with experimental ground vibration results. In order to account for inelastic behaviour of the soil and separation between the concrete slabs and the soil, a non-linear model of the coupled road-soil system is developed.

\section{Prediction of the impact load}

\subsection{Introduction}

Impact loads from sources such as pile driving [4], dynamic soil compaction [5, 6, 7], hammers and presses [8] are frequently studied using simple models consisting of rigid masses, dashpots, and springs. The impact of a rigid body on an elastic halfspace was studied theoretically and experimentally by Bycroft [9]. Chow et al. [10] have developed a one-dimensional (1D) finite element (FE) model for the simulation of pounder deceleration in dynamic soil compaction. The prediction of the impact load generated by a pavement breaker requires an accurate estimation of the flexibility of the pavement, accounting for the interaction with the underlying soil. In the following, a simplified model of the coupled system of pavement and soil is presented which allows limiting the computational cost of the simulation.

\subsection{Impact model}

The problem considered for the prediction of the impact load involves a hammer released at time $t=0$ from a height $h$, impacting the pavement at time $t_{0}=\sqrt{(2 h) / g}$, where $g$ denotes the gravitational acceleration. Since the drop hammer is much stiffer than the pavement [11], it is simplified as a rigid mass in the impact analysis. Before the impact $\left(0 \leq t<t_{0}\right)$, the vertical acceleration of the drop hammer $\ddot{u}_{\mathrm{d}}(t)=-g$, leading to an impact velocity $v_{0}=\dot{u}_{\mathrm{d}}\left(t_{0}\right)=-g t_{0}$ or $v_{0}=-\sqrt{2 g h}$ in terms of the drop height $h$. During impact, the drop hammer is subjected to the impact force $f_{\mathrm{d}}(t)$ and the gravitational force, so that the equation of motion becomes:

$$
f_{\mathrm{d}}(t)-m_{\mathrm{d}} g=m_{\mathrm{d}} \ddot{u}_{\mathrm{d}}(t) \quad \text { for } t_{0} \leq t \leq t_{0}+t_{\mathrm{d}}
$$

which is valid from $t_{0}$ until $t_{0}+t_{\mathrm{d}}$, at which the mass rebounds from the pavement and the impact ends. During impact, the drop hammer exerts an opposite contact force on the pavement, i.e. $f_{\mathrm{c}}(t)=-f_{\mathrm{d}}(t)$. Since the acceleration of the drop hammer during the impact is much larger than the acceleration of gravity, the corresponding term in equation (1) 
is omitted next. Once the acceleration $\ddot{u}_{\mathrm{d}}(t)$ has been computed, the contact force $f_{\mathrm{c}}(t)$ applied to the pavement can therefore be calculated from the acceleration of the drop hammer as:

$$
f_{\mathrm{c}}(t)=-m_{\mathrm{d}} \ddot{u}_{\mathrm{d}}(t) \quad \text { for } t_{0} \leq t \leq t_{0}+t_{\mathrm{d}}
$$

The contact force $f_{\mathrm{c}}(t)$ is related to the displacement of the pavement at the contact point $u_{\mathrm{c}}(t)$ through the dynamic stiffness of the system composed of pavement and underlying soil. This relation is written in the following general form:

$$
f_{\mathrm{c}}(t)=\int_{t_{0}}^{t} S(t-\tau) u_{\mathrm{c}}(\tau) \mathrm{d} \tau
$$

where $S(t)$ represents the dynamic stiffness of the coupled system [12]. When both systems are in perfect contact during the impact, $u_{\mathrm{c}}(\tau)$ can be replaced by $u_{\mathrm{d}}(\tau)$ in equation (3). Introducing the resulting expression for the contact force $f_{\mathrm{c}}(t)$ in equation (2) leads to the following integro-differential equation for the drop hammer displacement $u_{\mathrm{d}}(t)$ :

$$
\int_{t_{0}}^{t} S(t-\tau) u_{\mathrm{d}}(\tau) \mathrm{d} \tau=-m_{\mathrm{d}} \ddot{u}_{\mathrm{d}}(t) \quad \text { for } \quad t_{0} \leq t \leq t_{0}+t_{\mathrm{d}}
$$

which needs to be solved with initial conditions $u_{\mathrm{d}}\left(t_{0}\right)=0$ and $\dot{u}_{\mathrm{d}}\left(t_{0}\right)=-g t_{0}$.

The dynamic stiffness $S(t)$ represents the stiffness of the system composed of pavement and soil. By analogy with models developed for the dynamic response of flexible foundations, a linear model of a finite sized plate coupled to a layered halfspace model for the soil can be adopted for calculating the dynamic stiffness of the coupled system. The corresponding linear dynamic soil-structure interaction problem is solved efficiently in the frequency domain using coupled finite element - boundary element (FE-BE) methods. This has the additional advantage of transforming the convolution on the left hand side of equation (4) into a multiplication. For this reason, an equivalent frequency domain formulation of equation (4) with initial conditions $u_{\mathrm{d}}\left(t_{0}\right)=0$ and $\dot{u}_{\mathrm{d}}\left(t_{0}\right)=-g t_{0}$ is considered here. A pseudoforce $p(t)$ is introduced in equation (4) to account for non-zero initial conditions in the frequency domain analysis, following a procedure proposed by Humar [13], Clouteau and Aubry [14], and Martins et al. [15]. In the present case where only the initial velocity is different from zero, the pseudo-force required to produce a change in impulse from 0 to $m_{\mathrm{d}} v_{0}$ from $t=t_{0}^{-}$to $t=t_{0}^{+}$is equal to:

$$
p(t)=m_{\mathrm{d}} v_{0} \delta\left(t-t_{0}\right)
$$

where $\delta(t)$ is the Dirac delta function. Since the left hand side of equation (4) contains the force applied to the pavement, the pseudo-force is introduced with opposite sign to obtain the equivalent formulation of the problem with zero initial conditions $u_{\mathrm{d}}\left(t_{0}^{-}\right)=0$ and $\dot{u}_{\mathrm{d}}\left(t_{0}^{-}\right)=0$ :

$$
\int_{t_{0}}^{t} S(t-\tau) u_{\mathrm{d}}(\tau) \mathrm{d} \tau-m_{\mathrm{d}} v_{0} \delta\left(t-t_{0}\right)=-m_{\mathrm{d}} \ddot{u}_{\mathrm{d}}(t) \quad \text { for } \quad t_{0} \leq t \leq t_{0}+t_{\mathrm{d}}
$$

In the frequency domain, equation (6) reads as:

$$
\hat{S}(\omega) \hat{u}_{\mathrm{d}}(\omega)-m_{\mathrm{d}} v_{0}=m_{\mathrm{d}} \omega^{2} \hat{u}_{\mathrm{d}}(\omega)
$$

where $\omega$ is the angular frequency and a hat above a variable denotes its representation in the frequency domain. Solving for $\hat{u}_{\mathrm{d}}(\omega)$ and introducing the solution in equation (2), transformed to the frequency domain, gives the impact force:

$$
\hat{f}_{\mathrm{c}}(\omega)=\frac{m_{\mathrm{d}}^{2} \omega^{2} v_{0}}{\hat{S}(\omega)-m_{\mathrm{d}} \omega^{2}}
$$

Since the impact has a very short duration in the order of $1 \mathrm{~ms}$, the corresponding impact force has a broad band spectrum extending up to a few $\mathrm{kHz}$. This implies that the dynamic stiffness of the pavement $\hat{S}(\omega)$ is needed up to very high frequencies, requiring a significant computational cost. During the short duration of the impact, however, stress waves generated by the impact will only travel a limited distance, suggesting that the finite lateral dimensions 
of the slab will not have a major impact in the high frequency range. In the present work, the finite sized plate is therefore replaced by an elastic layer of infinite lateral dimenions and integrated in the layered elastic halfspace model representing the soil. Such systems can be analyzed very efficiently using the direct stiffness method [16, 17, 18]. In the following, the dynamic stiffness $\hat{S}(\omega)$ of the pavement is therefore computed considering a layered elastic halfspace model representing the pavement and the soil, subjected to a force uniformly distributed over a disc which represents the impact surface.

\subsection{Model parameters}

The simplified impact model is now applied to predict the impact load of the drop hammers of the MHB. For verification of the model, use is made of the measured acceleration of one of the hammers of a multi-head pavement breaker. The parameters of the MHB, the pavement, and the soil, adopted in the calculations, are briefly presented next.

\subsubsection{Properties of the drop hammers}

The drop hammers of the MHB are four steel cylinders with a diameter of $0.30 \mathrm{~m}$, a height of $1.0 \mathrm{~m}$, and a mass $m_{\mathrm{d}}=600 \mathrm{~kg}$ (figure 1). The MHB can release the drop hammers from two different heights of $1.3 \mathrm{~m}$ and $1.8 \mathrm{~m}$; a height $h=1.8 \mathrm{~m}$ is considered here. During its fall, the drop hammer has to return the hydraulic jack of the MHB to its original position which prevents the free fall of the drop hammer and reduces the impact velocity to $v_{0}=5.5 \mathrm{~m} / \mathrm{s}$, about $92 \%$ of the free fall velocity $(\sqrt{2 g h}=6 \mathrm{~m} / \mathrm{s})$. Since the bottom of the drop hammer is not completely flat, the impact footprint has a smaller diameter $d_{\mathrm{f}}=0.13 \mathrm{~m}$ than the steel cylinders. After the impact, a small rebound of the drop hammer occurs and a mechanism in the MHB prevents a second impact.

\subsubsection{Dynamic characteristics of the concrete road}

The N9 motorway is composed of concrete slabs with a width $2 B=2.85 \mathrm{~m}$, a thickness $t_{\mathrm{r}}=0.20 \mathrm{~m}$, and different lengths ranging from $4 \mathrm{~m}$ up to $12 \mathrm{~m}$. The following mechanical properties of the concrete have been obtained from three core samples [19] according to Eurocode 2 [20]: mean compressive strength of the standard cylindrical sample $f_{\mathrm{cm}}=78 \mathrm{MPa}$, dynamic modulus of elasticity $E_{\mathrm{c}}=43000 \mathrm{MPa}$, density $\rho_{\mathrm{c}}=2400 \mathrm{~kg} / \mathrm{m}^{3}$, and Poisson's ratio $v_{\mathrm{c}}=$ 0.20 . From these parameters, a shear wave velocity $C_{\mathrm{s}}=2732 \mathrm{~m} / \mathrm{s}$ and a dilatational wave velocity $C_{\mathrm{p}}=4462 \mathrm{~m} / \mathrm{s}$ are computed. A damping ratio $\beta_{\mathrm{s}}=\beta_{\mathrm{p}}=0.03$ for both the shear and dilatational waves is assumed. In the simplified model considered for the estimation of the impact load, the concrete pavement is integrated in the layered elastic halfspace model of the soil.

\subsubsection{Dynamic soil characteristics at small strains}

Borehole data reveal the presence of mostly sandy soils near the measurement site. The dynamic soil characteristics have been identified by means of in situ geophysical tests. Three methods have been combined to determine the shear and dilatational wave velocities $C_{\mathrm{s}}$ and $C_{\mathrm{p}}$ and the material damping ratios $\beta_{\mathrm{s}}$ and $\beta_{\mathrm{p}}$ : the seismic refraction method, the active Spectral Analysis of Surface Waves (SASW) test, and the passive SASW test [21]. Table 1 summarizes the thickness $t$ and identified soil parameters of each layer. Poisson's ratio $v$ has been computed from the shear and dilatational wave velocities. The soil density $\rho$, critical state friction angle $\phi_{c v}^{\prime}$, and dilatancy angle $\psi$ of the first four layers are obtained from the data of six Cone Penetration Tests (CPT) near the measurement site [22, 23]. The density of the deeper layers is assumed to be equal to $\rho=2000 \mathrm{~kg} / \mathrm{m}^{3}$.

Bolton and Wilson [24] have found from cyclic tests on sand that the stiffness and damping of the soil are independent of the strain rate. Therefore, the identified soil parameters in table 1 are not modified and used in the following to validate a numerical model for the estimation of the impact load and for the prediction of ground vibrations generated by pavement breaking.

\subsection{Verification of the simplified model}

The dynamic stiffness $\hat{S}(\omega)$ obtained from the simple horizontally layered halfspace model is now verified by means of a 3D coupled FE-BE which considers the finite lateral dimensions of the concrete slabs. The BE formulation is based on the Green's functions of a horizontally layered halfspace. A slab with a width $2 B=2.85 \mathrm{~m}$ and length $2 L=4.60 \mathrm{~m}$ is considered in the 3D model and modelled by means of $48 \times 704$-node shell elements with 6 DOFs at 
Table 1: Dynamic soil characteristics at the measurement site in Waarschoot.

\begin{tabular}{lcccccccc}
\hline Layer & $t$ & $C_{\mathrm{s}}$ & $C_{\mathrm{p}}$ & $\mathrm{v}$ & $\rho$ & $\beta_{\mathrm{s}}$ and $\beta_{\mathrm{p}}$ & $\phi_{c v}^{\prime}$ & $\psi$ \\
& {$[\mathrm{m}]$} & {$[\mathrm{m} / \mathrm{s}]$} & {$[\mathrm{m} / \mathrm{s}]$} & {$[-]$} & {$\left[\mathrm{kg} / \mathrm{m}^{3}\right]$} & {$[-]$} & {$[\mathrm{deg}]$} & {$[\mathrm{deg}]$} \\
\hline 1 & 1.8 & 159 & 562 & 0.46 & 1920 & 0.031 & 33 & 9 \\
2 & 1.8 & 159 & 562 & 0.46 & 1920 & 0.031 & 37 & 11 \\
3 & 2.3 & 159 & 1465 & 0.49 & 1860 & 0.038 & 33 & 3 \\
4 & 2.2 & 240 & 1465 & 0.49 & 2000 & 0.039 & 39 & 9 \\
5 & 4.1 & 240 & 1579 & 0.49 & 1960 & 0.040 & - & - \\
6 & 4.0 & 250 & 1829 & 0.49 & 2000 & 0.040 & - & - \\
7 & 2.7 & 255 & 2000 & 0.49 & 2000 & 0.040 & - & - \\
8 & 7.4 & 328 & 2000 & 0.49 & 2000 & 0.040 & - & - \\
9 & 12.5 & 400 & 2000 & 0.48 & 2000 & 0.040 & - & - \\
\multicolumn{2}{l}{ Halfspace $\infty$} & 500 & 2000 & 0.47 & 2000 & 0.040 & - & - \\
\hline
\end{tabular}

each node. The FE model of the slab is coupled to a BE model for the soil, considering welded boundary conditions at the interface between both models. The boundary elements are 4-node quadrilateral elements with linear shape functions. Chosing a conforming BE mesh provides at least six boundary elements per wavelength up to $400 \mathrm{~Hz}$, as recommended by Kuhlemeyer and Lysmer [25]. This is sufficient to cover the frequency range of interest for ground borne vibration generated by the pavement breaker. The impact is applied as a point load on the FE slab model and the dynamic stiffness is computed as the ratio of the applied force and the displacement of the loaded node.

In the $3 \mathrm{D}$ model, the dynamic stiffness of the pavement depends on the position where the load is applied. Figure 2 compares the real and imaginary part of the dynamic stiffness $\hat{S}(\omega)$ computed with the simplified model to the dynamic stiffness computed with the $3 \mathrm{D}$ FE-BE model for a load at the centre of the slab $\mathbf{x}_{\mathrm{s}}=\left\{0,0, t_{\mathrm{r}}\right\}^{\mathrm{T}}$, at a point near the edge of the slab $\mathbf{x}_{\mathrm{s}}=\left\{0.75 \mathrm{~m}, 0, t_{\mathrm{r}}\right\}^{\mathrm{T}}$, and at a point near the corner of the slab $\mathbf{x}_{\mathrm{s}}=\left\{0.75 \mathrm{~m}, 2.0 \mathrm{~m}, t_{\mathrm{r}}\right\}^{\mathrm{T}}$.
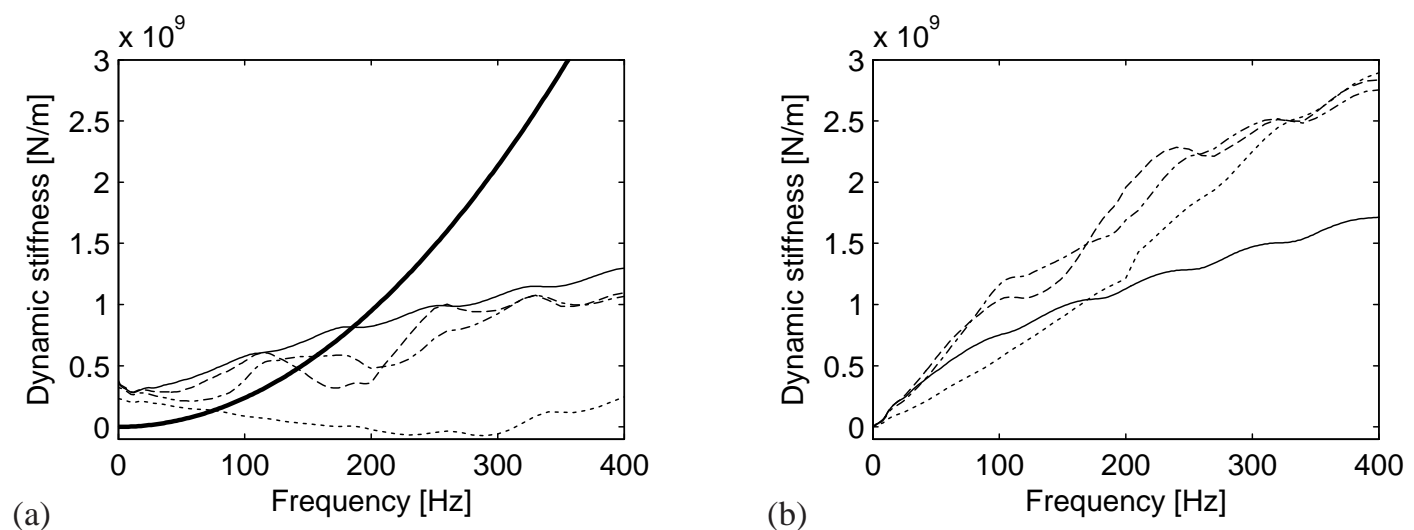

Figure 2: (a) Real and (b) imaginary part of the dynamic stiffness $\hat{S}(\omega)$ of the pavement computed with the layered halfspace model (thin solid line) and the 3D FE-BE model for a load at the centre of the slab $\mathbf{x}_{\mathrm{s}}=\left\{0,0, t_{\mathrm{r}}\right\}^{\mathrm{T}}$ (dashed line), near the edge $\mathbf{x}_{\mathrm{s}}=\left\{0.75 \mathrm{~m}, 0, t_{\mathrm{r}}\right\}^{\mathrm{T}}($ dashed-dotted line), and near the corner $\mathbf{x}_{\mathrm{s}}=\left\{0.75 \mathrm{~m}, 2.0 \mathrm{~m}, t_{\mathrm{r}}\right\}^{\mathrm{T}}$ (dotted line). Superimposed on (a) is the mass inertia $m_{\mathrm{d}} \omega^{2}$ of the drop hammer (thick line).

At very low frequencies, the results for the layered halfspace model and the 3D finite slab model are very close, in particular when, in the latter model, the load is applied at the centre of the slab or near the edge. Up to $400 \mathrm{~Hz}$, the results of the layered halfspace model and the 3D model are in close agreement, except when the load is applied at the corner of the slab. Since the impact force in equation (8) depends on the sum of the dynamic stiffness of the pavement $\hat{S}(\omega)$ and the inertia of the drop hammer $-m_{\mathrm{d}} \omega^{2}$, differences in the results for the dynamic stiffness will only affect the predicted impact force when they are large compared to the inertia of the drop hammer. Therefore, the absolute value of the inertia $-m_{\mathrm{d}} \omega^{2}$ of the drop hammer has been superimposed in figure $2 \mathrm{a}$. These results show that, at high frequencies, the inertia of the drop hammer becomes more important than differences observed between the results of the different models and load positions. The simplified layered halfspace model is therefore used to calculate the 
impact force of the drop hammers.

\subsection{Experimental validation of the predicted impact load}

In order to estimate the impact force, the recorded acceleration of the drop hammer is multiplied by its mass $m_{\mathrm{d}}$, following equation (2). Figure 3 compares the experimental impact force with the force predicted by the simplified pavement model. Figure 3a shows that the duration of the impact is well predicted while the peak value of the force is slightly overestimated. Figure $3 b$ shows that the frequency content of the experimental force is mainly situated below $900 \mathrm{~Hz}$. The dip at $900 \mathrm{~Hz}$ is related to the impact duration $t_{\mathrm{d}}$ as $2 / t_{\mathrm{d}} \approx 900 \mathrm{~Hz}$. The predicted force follows a similar trend as the experimental force. In the narrow band frequency spectrum of the measured force, sharp peaks are observed around $1100 \mathrm{~Hz}$ and $2400 \mathrm{~Hz}$ which correspond to the natural vibration modes of the drop hammer [11]. Since a rigid mass model has been adopted for the calculation of the impact force, these peaks are not found in the predicted force. In general, the agreement between both results is considered satisfactory and the impact load computed by the simplified model is used next to predict ground vibrations induced by the MHB.
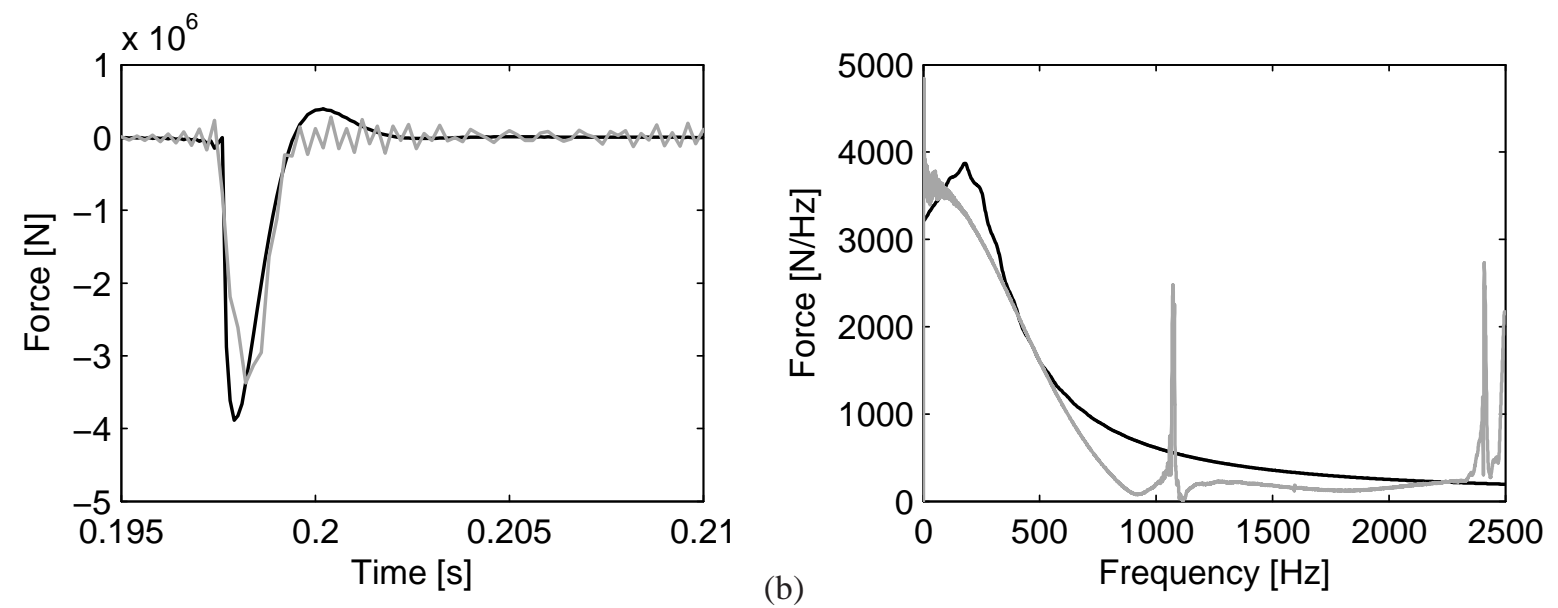

Figure 3: Predicted (black line) and measured (grey line) (a) time history and (b) narrow band frequency spectrum of the impact force.

\section{Prediction of ground vibrations}

\subsection{Introduction}

The prediction of ground vibration due to the operation of the MHB is a challenging problem because of the high stress and strain levels that are generated in the pavement and the underlying soil. A first issue to be considered in the development of a numerical model is the fracturing of the concrete due to the pavement breaker. The aim of the fracturing is to transform the deteriorated concrete pavement into a suitable foundation for the asphalt overlay. The drop height is therefore chosen such that the pavement is broken into pieces of about $1 \mathrm{~m}^{2}$, separated by hairline cracks, without significant crushing of concrete. In these fine cracks, aggregate interlock still occurs [26] and fracturing is not expected to significantly affect the distribution of the impact load by the pavement, nor the resulting levels of ground vibration. This was confirmed by measurements were no large differences were found in ground vibration levels generated by eight consecutive impacts at four points of a single concrete slab. The entire unfractured slab is therefore considered in the model [11].

The energy dissipated by the fracturing of the concrete was estimated based on the crack pattern observed during the operation of the MHB and fracture energy estimates for similar cases reported in the literature [27, 28]. It was concluded that at most $10 \%$ of the impact energy would go to the fracturing of the concrete, implying that most of the energy is transferred into the soil. For this reason, the energy dissipated by concrete fracturing and inelastic behaviour of the concrete slab are disregarded in the model. 
The impact loads transferred by the concrete slab to the soil lead to very high strain levels of the order of a few millistrain [22]. Plastic deformation is expected to occur in a rather large volume of soil underneath the concrete slab, dissipating a significant part of the impact energy. A non-linear model is therefore needed that accounts for inelastic soil behaviour.

\subsection{Methodology}

Inelastic soil behaviour will mainly occur close to the concrete slab, while further away, the strain levels will be sufficiently small to remain within the elastic range. A distinction is therefore made between two subdomains $\Omega_{\mathrm{i}}$ and $\Omega_{\mathrm{e}}$ (figure 4a). The subdomain $\Omega_{\mathrm{i}}$ consists of the slab and the volume of soil with inelastic behaviour; it is bounded by the free surface $\Gamma_{\mathrm{i} \sigma}$. The subdomain $\Omega_{\mathrm{e}}$ is the halfspace of soil with elastic behaviour, bounded by the free surface $\Gamma_{\mathrm{e} \sigma}$ and the outer boundary $\Gamma_{\mathrm{e} \infty}$. The interface between the subdomains $\Omega_{\mathrm{i}}$ and $\Omega_{\mathrm{e}}$ is denoted as $\Sigma_{\mathrm{ie}}$.

It is advantageous from a computational point of view to perform the analysis in two stages. In the first stage, the domain $\Omega_{1}$ is considered which contains the concrete slab and a bounded volume of soil, including the subdomain $\Omega_{\mathrm{i}}$ with inelastic soil behaviour (figure $4 \mathrm{~b}$ ). The domain $\Omega_{1}$ is bounded by the free surface $\Gamma_{1 \sigma}$ and the boundary $\Gamma_{\mathrm{v}}$, which is chosen such that a path $\Sigma$ can be defined in the part of $\Omega_{1}$ with elastic soil behaviour. In order to account for non-linear behaviour of the soil in $\Omega_{1}$, a time domain FE method with local absorbing boundary conditions along the boundary $\Gamma_{\mathrm{v}}$ is used in the first stage of the analysis [29, 12].

In the second stage of the analysis, the displacements and tractions computed along the path $\Sigma$ are used to predict the transfer of ground vibration in the region of soil with elastic behaviour. The second model consists of the halfspace $\Omega_{\mathrm{s}}$, bounded by the free surface $\Gamma_{\mathrm{s} \sigma}$ and the outer boundary $\Gamma_{\mathrm{s} \infty}$ (figure $4 \mathrm{c}$ ). The integral representation theorem of elastodynamics is used to compute the response of the domain outside $\Sigma$ from the displacements and tractions along $\Sigma$. A frequency domain boundary element method is applied for this purpose.

In the following, a numerical verification of the two-step approach for a linear analysis is presented first. Next, the non-linear model used for the prediction of ground vibration due to the pavement breaker is discussed and the results are compared to measured ground vibration.

\subsection{Numerical verification for linear elastic soil behaviour}

In the following, the proposed two-stage approach is verified assuming elastic soil behaviour. The slab is not included in the model to enable comparison to a reference solution for a layered halfspace obtained by means of the direct stiffness method [16, 17, 18]. The two-stage approach is verified by comparing the response of both models obtained for the predicted impact load of the MHB (figure 3). Since elastic soil behaviour is assumed, the relevant material properties of each layer are the wave velocities $C_{\mathrm{s}}$ and $C_{\mathrm{p}}$, the corresponding material damping ratios $\beta_{\mathrm{p}}$ and $\beta_{\mathrm{s}}$, and the density $\rho$ listed in table 1 . The material damping ratios correspond to a hysteretic damping model which provides a good fit to experimental results in the frequency domain but violates causality. Therefore, an equivalent viscous damping is considered for each layer. The element damping matrix $\mathbf{C}^{\mathrm{e}}$ is calculated from the element stiffness matrix $\mathbf{K}^{\mathrm{e}}$ through a multiplier $\eta^{\mathrm{e}}$, so that $\mathbf{C}^{\mathrm{e}}=\eta^{\mathrm{e}} \mathbf{K}^{\mathrm{e}}$. The multiplier $\eta^{\mathrm{e}}$ is calculated from the hysteretic material damping ratio $\beta$ of each layer as $\eta^{e}=2 \beta / \omega_{0}$, where $\omega_{0}$ is a normalization frequency at which the energy dissipation in both models is identical. A low normalisation frequency $\omega_{0}$ leads to a stronger attenuation of the high frequency response in comparison to the hysteretic material damping model while a high normalisation frequency leads to an underestimation of energy dissipation at low frequencies. In the present analysis, a normalization frequency $\omega_{0} /(2 \pi)=100 \mathrm{~Hz}$ is chosen. In the frequency domain reference solution obtained by means of the direct stiffness method $[16,17,18]$, the material damping ratio $\beta_{\mathrm{s}}$ and $\beta_{\mathrm{p}}$ of the shear and dilatational waves, respectively, are chosen frequency dependent $\beta_{\mathrm{s}}=\beta_{\mathrm{p}}=\left(\eta^{\mathrm{e}} \omega\right) / 2$, corresponding to the viscous damping in the FE model.

An axisymmetric FE model of the soil is considered to reduce the computational costs. The axisymmetric FE model has a width $B_{\mathrm{S}}=6 \mathrm{~m}$ and a depth $D_{\mathrm{s}}=8.1 \mathrm{~m}$. The material properties are chosen according to the first four layers of the soil profile in table 1, disregarding changes in the soil properties below $8.1 \mathrm{~m}$. The soil domain is modelled in ANSYS using 8-node quadrilateral elements (figure 6a), where a distinction is made between a near field zone with a target element size of $0.02 \mathrm{~m}$ and a far field zone with an element size of $0.06 \mathrm{~m}$. In addition, a local mesh refinement has been considered around the load point. The resulting mesh provides at least 4 elements per wavelength upto a frequency of $500 \mathrm{~Hz}$.

The impact force is applied considering an impact footprint with a radius $d_{\mathrm{f}} / 2=0.065 \mathrm{~m}$. 


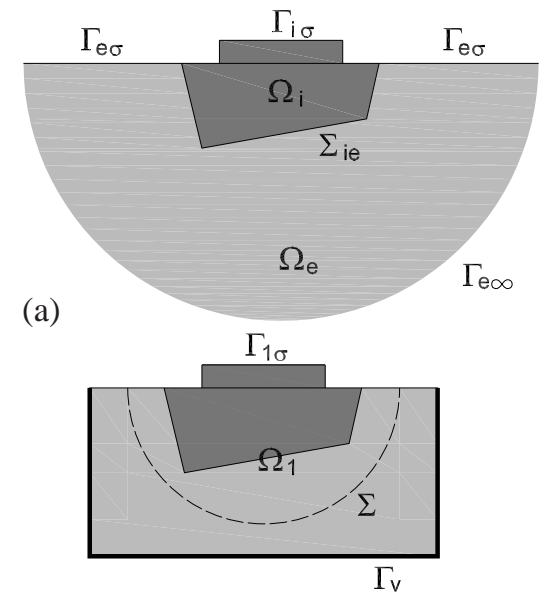

(b)

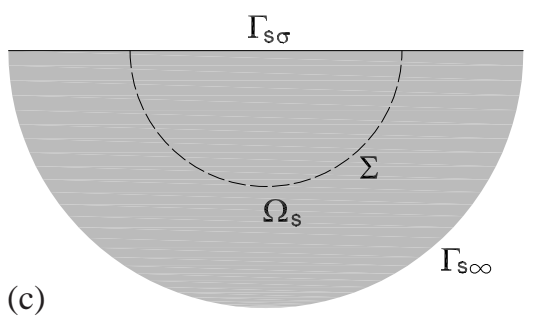

Figure 4: (a) Coupled inelastic and elastic subdomains $\Omega_{\mathrm{i}} \cup \Omega_{\mathrm{e}}$, (b) the inelastic region and a part of the elastic domain $\Omega_{1}$ coupled to the local absorbing boundary $\Gamma_{\mathrm{v}}$, and (c) the elastic halfspace $\Omega_{\mathrm{s}}$.

At the boundaries of the FE mesh, local absorbing boundary conditions are applied to avoid spurious reflections. This is achieved through the use of viscous dampers parallel and perpendicular to the boundary in order to absorb shear and dilatational waves, respectively.

The solution is obtained by means of a direct time integration in ANSYS, assuming linear displacements. A Newmark time integration method is selected with parameters $\alpha=0.2525$ and $\delta=0.5050$.

The displacements $\underline{\mathbf{u}}_{\mathrm{p}}(t)$ and tractions $\underline{\mathbf{t}}_{\mathrm{p}}(t)$ along the path $\Sigma$ inside the FE domain (figure 4c) are now used to compute the response at larger distance from the source. The path $\Sigma$ is chosen at a distance $B_{\mathrm{b}}=4 \mathrm{~m}$ from the vertical axis and at a depth $D_{\mathrm{b}}=5 \mathrm{~m}$. The integral representation theorem is used to compute the radiated wave field $\underline{\hat{\mathbf{u}}}(\omega)$ in the domain $\Omega_{\mathrm{s}}$ from the Fourier transform of the displacements $\underline{\underline{\hat{u}}}_{\mathrm{p}}(\omega)$ and tractions $\underline{\mathbf{t}}_{\mathrm{p}}(\omega)$ :

$$
\underline{\hat{\mathbf{u}}}(\omega)=\hat{\mathbf{U}}_{\mathrm{r}}(\omega) \underline{\hat{\mathbf{t}}}_{\mathrm{s}}(\omega)-\hat{\mathbf{T}}_{\mathrm{r}}(\omega) \underline{\hat{\mathbf{u}}}_{\mathrm{s}}(\omega)
$$

where $\hat{\mathbf{U}}_{\mathrm{r}}(\omega)$ and $\hat{\mathbf{T}}_{\mathrm{r}}(\omega)$ are boundary element transfer matrices based on the Green's functions of a horizontally layered halfspace. The Green's functions are computed using the direct stiffness method [16, 17, 18], assuming hysteretic material damping. The boundary element discretisation consists of 3-node line elements with quadratic shape functions. The boundary elements have a size of $0.08 \mathrm{~m}$ which is similar to the finite elements located along the path $\Sigma$. Since a non-conforming BE mesh is used, the displacements and tractions on the BE mesh are computed by interpolation.

Figure 5 compares the vertical velocity predicted using the two-stage approach to the results of the direct stiffness method at a receiver $\mathbf{x}=\{2 \mathrm{~m}, 0,-2\}^{\mathrm{T}}$ located inside the $\mathrm{FE}$ domain and a receiver $\mathbf{x}=\{10 \mathrm{~m}, 0,0\}^{\mathrm{T}}$ at the soil's surface outside the FE domain. The response at the first point is found from the FE model, while the integral representation theorem (9) is applied to compute the response at the second point. Figure 5 shows that the agreement between the results of the finite element model and the direct stiffness method is very good. 

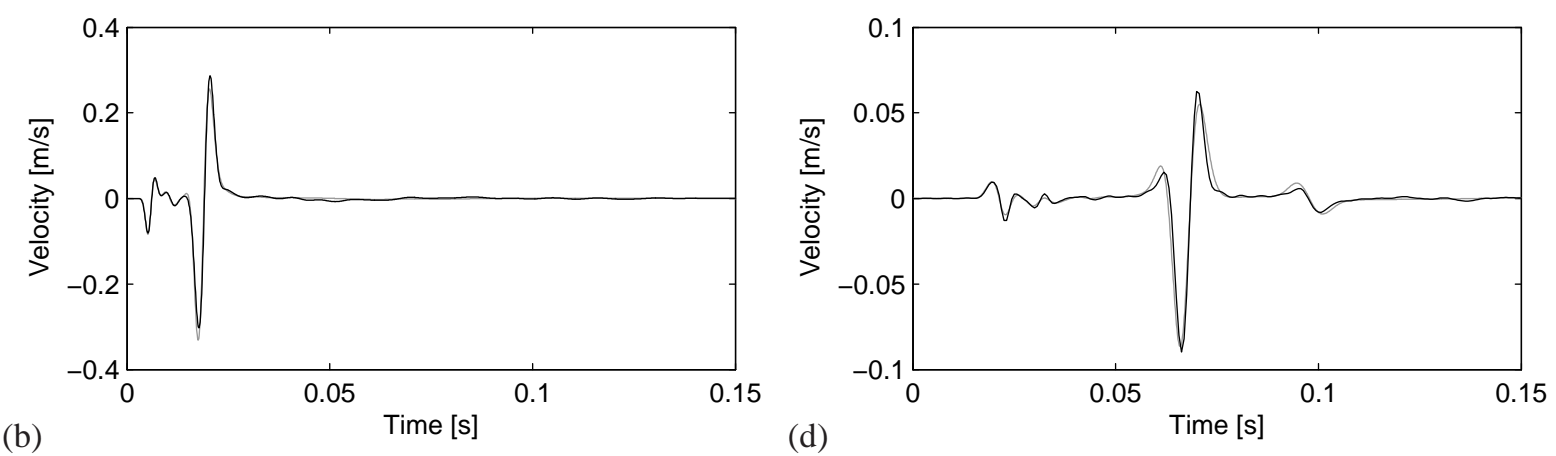

Figure 5: Time history of the vertical velocity at (a) $\mathbf{x}=\{2 \mathrm{~m}, 0,-2 \mathrm{~m}\}^{\mathrm{T}}$ and (b) $\mathbf{x}=\{10 \mathrm{~m}, 0,0\}^{\mathrm{T}}$ due to an impact of the MHB on the soil surface computed with the FE and the accompanying BE model (black line) compared to the results of the direct stiffness method assuming a frequency dependent damping (grey line).

\subsection{Non-linear model}

This subsection describes the non-linear model that has been used to account for inelastic soil behaviour in the prediction of the ground vibration generated by the MHB. Because of the limited information available on strength parameters for the soil, the inelastic soil behaviour is modelled by the Drucker-Prager yield criterion with a nonassociative flow rule, assuming elastic-perfectly plastic constitutive behaviour. The use of more advanced models $[30,31,32]$ would allow to better describe the dynamic response of the soil underneath the foundation, but require a large number of material parameters. The available soil parameters, including elastic and limit state soil parameters is presented in table 1. Since the shear strength depends on the normal stresses in the soil, the self weight of the slab and the soil are considered in the analysis. The slab is assumed to have a circular shape to obtain an axisymmetric problem geometry. The FE model is composed of the slab and a cylinder of soil with a radius $B_{\mathrm{S}}=6 \mathrm{~m}$ and a height $D_{\mathrm{s}}=8.1 \mathrm{~m}$. The dimensions of the soil domain have been estimated from preliminary analyses. The domain is meshed using 8-node quadrilateral elements in ANSYS. A similar mesh is used as for the linear analysis, considering a near field zone (including the slab) with a target element size of $0.033 \mathrm{~m}$ and a far field zone with an element size of $0.10 \mathrm{~m}$ (figure 6b). In addition, a local mesh refinement has been considered around the load point. The damping matrix $\mathbf{C}^{\mathrm{e}}$ of the elements is computed assuming Rayleigh damping. Since the main source of energy dissipation is the inelastic material behaviour, a high normalisation frequency $\omega_{0} /(2 \pi)=200 \mathrm{~Hz}$ is chosen to compute $\eta^{\mathrm{e}}=2 \beta / \omega_{0}$ in each soil layer. At the truncated boundaries of the soil domain, local absorbing boundary conditions are applied.

Preliminary analyses assuming perfect contact between the slab and the soil resulted in unrealistic tensile stresses at the interface, revealing a tendency of slab uplifting. In order to account for separation of the slab and the soil during the impact, the contact-target pair model $[33,34]$ is employed. On the slab-soil interface, the bottom surface of the slab is modelled with 3-node 2D target elements (TARGE169) and 3-node 2D contact elements (CONTA172) are used on the soil surface with the default ANSYS key options. The surface-to-surface contact model includes both the normal pressure and frictional stresses and allows sliding and separation of the contacting surfaces, where a friction coefficient $\mu=0.4$ is considered. The contact problem is solved by means of the augmented Lagrangian method $[33,34]$. This is an iterative method where the contact tractions are augmented at each iteration so that the final penetration is smaller than an allowable tolerance. The tolerance was chosen such that the final penetration was less than $1 \%$ of the height of the quadrilateral plane elements below the contact surface.

The response of the soil is computed in two steps. First, the self-weight of the soil is applied. The solution is found in ANSYS using a static large displacement analysis with standard solution control options. In a second step, the impact load is applied and a direct time integration with Newmark parameters $\alpha=0.2525$ and $\delta=0.5050$ is performed, accounting for large displacements. Automatic time stepping is activated, with an initial time step $\Delta t_{0}=10^{-4} \mathrm{~s}$ that is allowed to vary between $\Delta t_{\min }=10^{-6} \mathrm{~s}$ and $\Delta t_{\max }=5 \times 10^{-4} \mathrm{~s}$. A standard Newton-Raphson iteration with line search convergence acceleration is selected for the solution of the non-linear equilibrium in each time step, limiting the number of iterations to $N_{\text {iter }}^{\max }=30$.

The integral representation theorem (9) is used to compute the response at larger distances from the displacements and tractions along a path $\Sigma$ at a distance $B_{\mathrm{b}}=4 \mathrm{~m}$ and depth $D_{\mathrm{b}}=5 \mathrm{~m}$. In the FE analysis, the self weight of the 


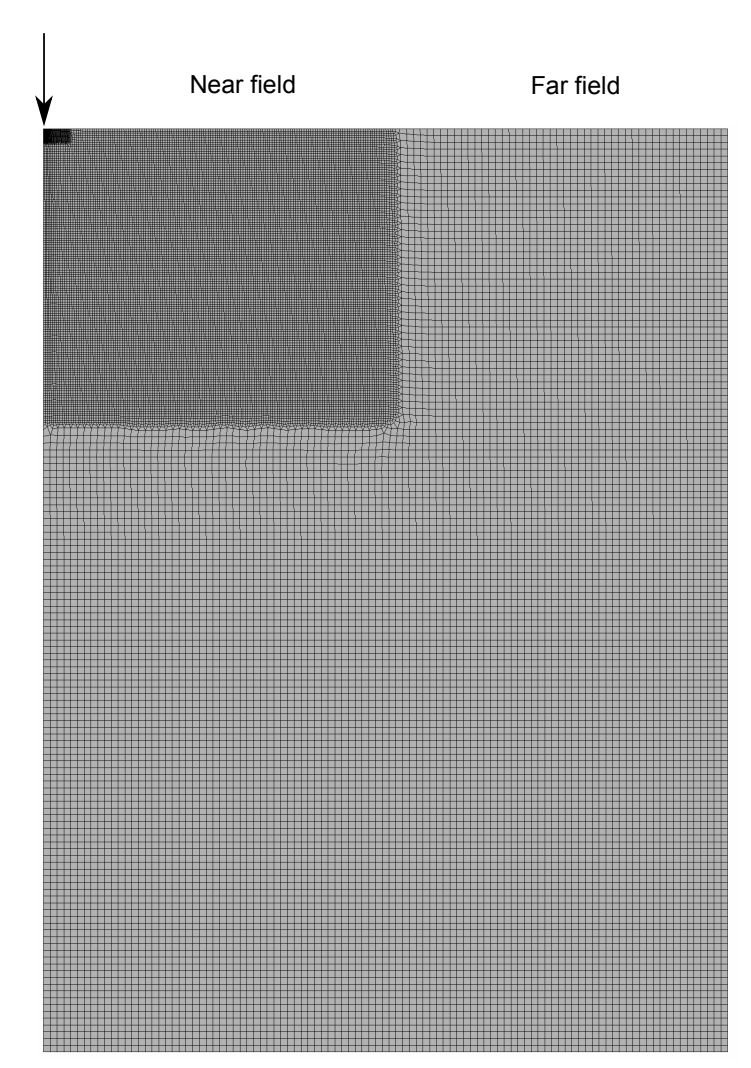

(a)

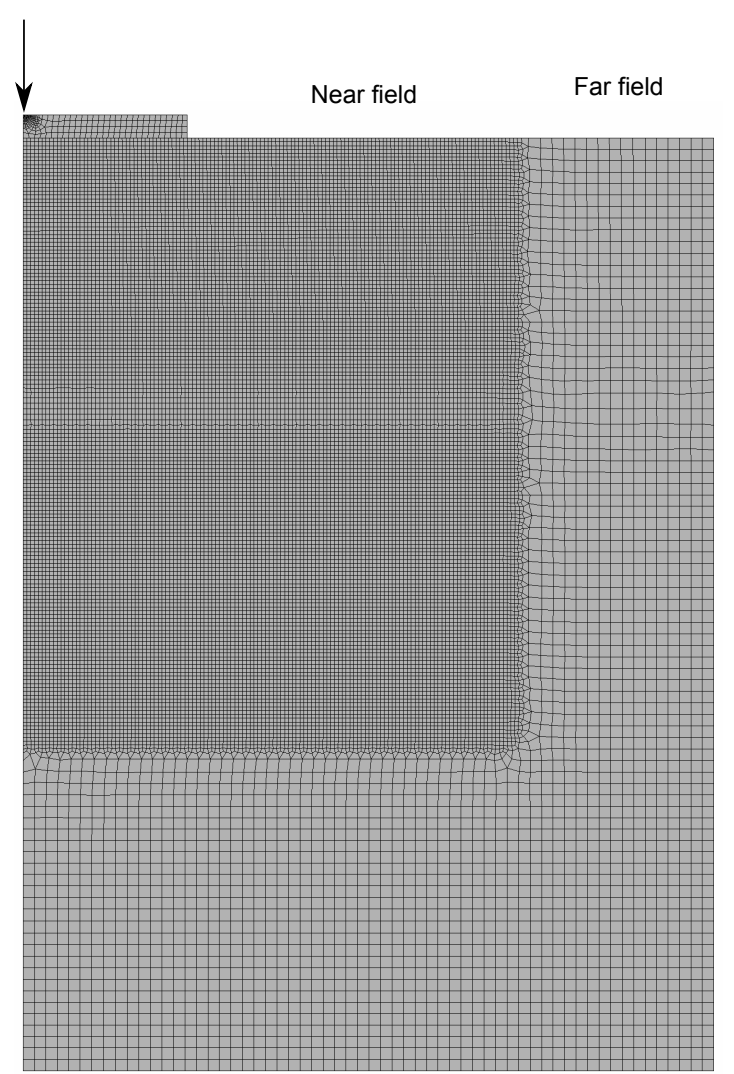

(b)

Figure 6: Axisymmetric FE mesh of (a) the layered halfspace used for the numerical verification of the linear elastic soil behaviour and (b) the slab founded on the layered halfspace used for the calculation of the non-linear soil response.

soil is accounted for, so that the initial displacements and tractions, prior to the impact, are non-zero. The permanent displacements and tractions after the impact differ from these initial values due to the inelastic behaviour of the soil. Computation of the radiated wave field using equation (9) requires a Fourier transform of the displacements and tractions at $\Sigma$. When a Fast Fourier Transform algorithm is applied, these response quantities are assumed to be periodic in time and the initial and final values need to be identical to avoid a step-wise change. This was enforced using a time window to gradually change the final values to their initial values. The time window applied is the modulus of the transfer function of a second order Butterworth filter with a cut-off at $0.7 T$ with $T$ the time period.

\subsection{Results}

In the analysis, the self weight of the slab and the soil is applied first. Figure 7a shows the displacement field in the slab and the soil before the impact (at $t=1.000 \mathrm{~s}$ ). Figure $8 \mathrm{a}$ shows the corresponding normal stress $\sigma_{z z}$ in the slab and the soil which gradually increases with depth due to the self weight.

The impact load (figure 3 ) is applied $1 \mathrm{~ms}$ after the application of the self weight, from $t=1.001 \mathrm{~s}$ until $t=1.003 \mathrm{~s}$. Snap shots of the displacement field at times $t=1.003 \mathrm{~s}, t=1.008 \mathrm{~s}$, and $1.500 \mathrm{~s}$ are shown in figures $7 \mathrm{~b}, 7 \mathrm{c}$, and $7 \mathrm{~d}$, respectively. The slab first moves downwards due to the impact (figure 7b), inducing permanent deformation of the soil, and lifts up (figure 7c). After some time, the slab returns to the soil surface and rebounds. Finally, the edges of the slab rest on the deformed surface of the soil while a void forms under the location of the impact (figure $7 \mathrm{~d}$ ). The impact leads to permanent vertical displacements of the slab and the soil under the slab of $-0.22 \mathrm{~mm}$ and $-2.99 \mathrm{~mm}$, respectively. Figure $8 \mathrm{~b}$ shows that the impact changes the stress distribution near the slab with residual stresses below the slab due to the inelastic behaviour of the soil. 


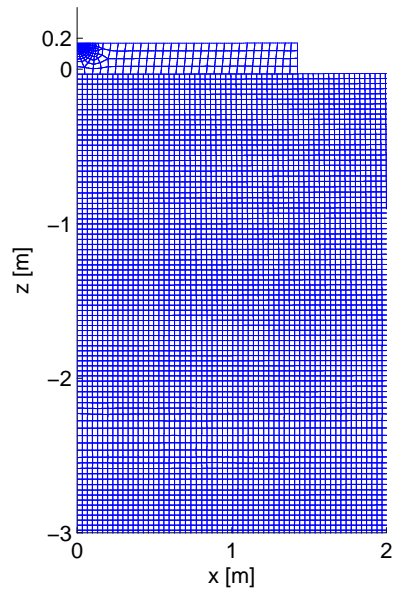

(a)

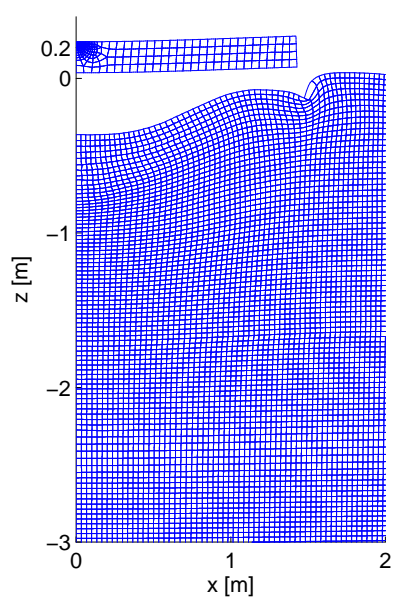

(c)

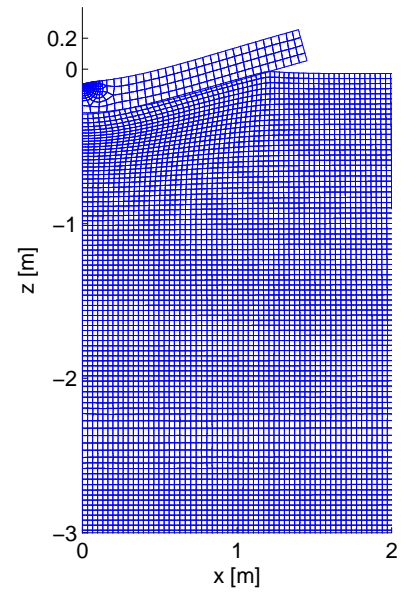

(b)

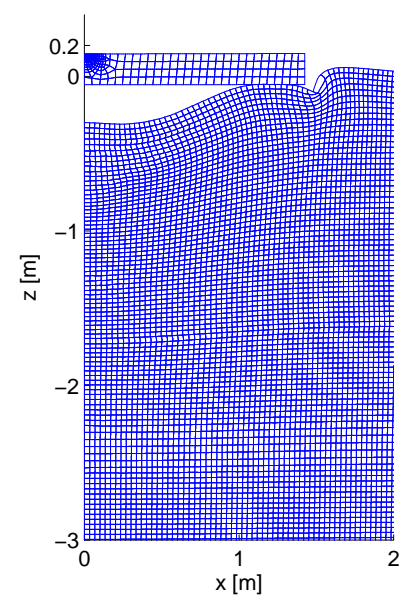

(d)

Figure 7: Displacement field in the slab and the soil at (a) $t=1.0 \mathrm{~s}$, (b) $t=1.003 \mathrm{~s}$, (c) $t=1.008 \mathrm{~s}$, and (d) $t=1.500 \mathrm{~s}$ due to an impact of the MHB. The displacements are scaled by a factor of 100 .

Figure 9 shows snap shots of the vertical velocity in the FE domain at $t=1.003 \mathrm{~s}$ (after the impact) and $t=1.008 \mathrm{~s}$. Vibration velocities superior to $50 \mathrm{~mm} / \mathrm{s}$ are found in the entire domain. No significant wave reflections from the local absorbing conditions are observed.

Figure 10 shows the volume of soil where plastic deformation occurs due to the impact. The plastic deformation in the soil is mainly concentrated under the slab. The path $\Sigma$ which is assumed to be located in the region with elastic material behaviour slightly cuts through the plastic region. The level of plastic deformation in this region is very small, however, so that this will not significantly affect the prediction of vibration at larger distances from the source in the second stage of the analysis. The sudden change at a depth of $1.6 \mathrm{~m}$ occurs at the interface between layers.

Figure 11 shows the elastic and plastic part of the octahedral shear strain in the volume of soil considered in the FE analysis. The shear strain is mostly elastic down to $0.2 \mathrm{~m}$ under the centre of the slab. Here, the confining pressure is also very large, so that the soil behaviour is elastic according to the Drucker-Prager criterion. At a larger depth of about $0.6 \mathrm{~m}$ below the slab as well as near the edge of the slab, the deformations are mostly plastic. The octahedral shear strain in the soil domain is less than 0.007 except under the edge of the slab where stresses and strains are very large.

Figure 12 shows the square root of the second deviatoric stress invariant $\mathrm{I}_{2 \mathrm{~s}}$ versus the mean pressure $\mathrm{I}_{1 \sigma}$ at 9 points in the soil domain, located at depths $z=0,-0.5 \mathrm{~m}$, and $-1.5 \mathrm{~m}$ and radial distances $x=0.1 \mathrm{~m}, 1.0 \mathrm{~m}$, and $1.5 \mathrm{~m}$. 

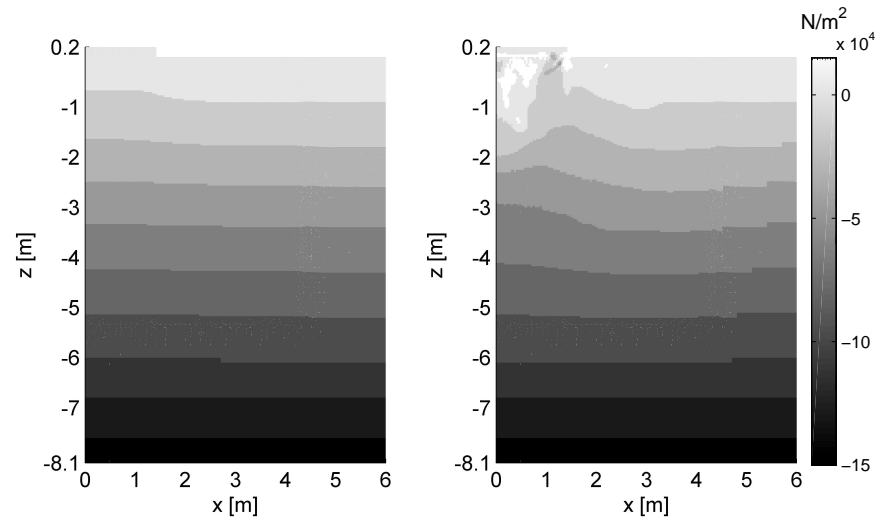

(a)

(b)

Figure 8: Predicted normal stress $\sigma_{z z}$ in the slab and the soil (a) before and (b) after the impact.

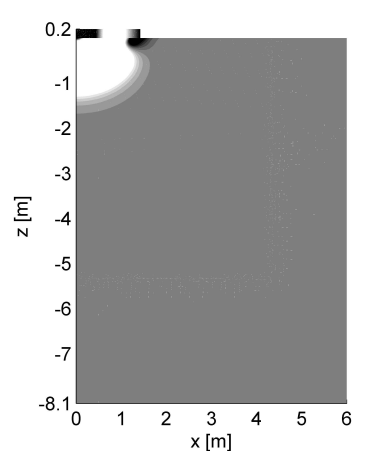

(a)

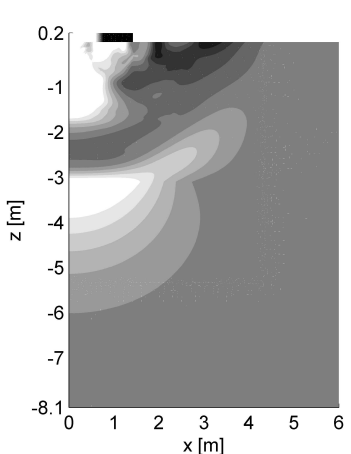

(b)

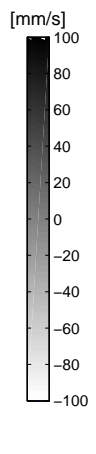

Figure 9: Vertical vibration velocity at (a) $t=1.003 \mathrm{~s}$ and (b) $t=1.008 \mathrm{~s}$ generated by an impact of the MHB.

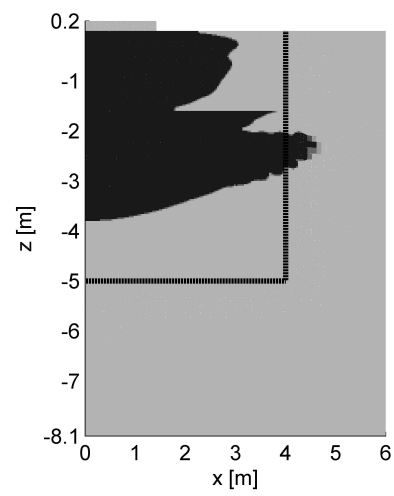

Figure 10: Elastic region (grey) and plastic region (black) in the FE domain due to an impact of the MHB. Superimposed is the position of the path $\Sigma$ (thick line).

Figure 12a shows that $I_{1 \sigma}$ at $\mathbf{x}=\{0.1 \mathrm{~m}, 0,0\}^{\mathrm{T}}$ reaches a value of $1700 \mathrm{kPa}$ while $\sqrt{\mathrm{I}_{2 \mathrm{~s}}}$ is about $340 \mathrm{kPa}$. The ratio $\sqrt{\mathrm{I}_{2 \mathrm{~s}}} / \mathrm{I}_{1 \sigma}$ is small which, according to the Drucker-Prager yield criterion, results in large elastic and small plastic 


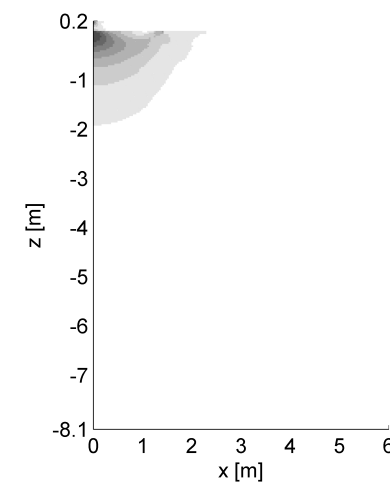

(a)

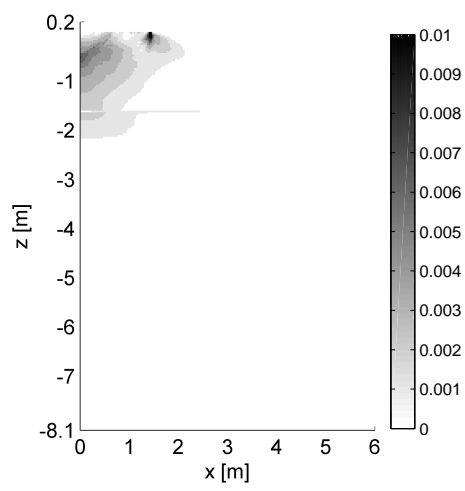

(b)

Figure 11: (a) Elastic and (b) plastic part of the octahedral shear strain due to an impact of the MHB.

deformation (figures 11a and 11b). Figure $12 \mathrm{~b}$ shows that the stress conditions at $\mathbf{x}=\{1 \mathrm{~m}, 0,0\}^{\mathrm{T}}$ are similar to those at $\mathbf{x}=\{0.1 \mathrm{~m}, 0,0\}^{\mathrm{T}}$. Near the edge of the slab at $\mathbf{x}=\{1.5 \mathrm{~m}, 0,0\}^{\mathrm{T}}$ (figure 12c), the deviatoric stress is much larger than the mean pressure because the point is at the free surface of the soil. This results in large plastic strains. The points at the depth $z=-0.5 \mathrm{~m}$ (figures $12 \mathrm{~d}$ and $12 \mathrm{e}$ ) are subjected to large shear stresses, leading to large plastic strains (figure 11b). At the depth $z=-1.5 \mathrm{~m}$, the ratio $\sqrt{\mathrm{I}_{2 \mathrm{~s}}} / \mathrm{I}_{1 \sigma}$ is small and thus the plastic strains are small. For all points except the point $\{1.5 \mathrm{~m}, 0,0\}^{\mathrm{T}}$ near the edge of the slab, the mean pressure is found to increase as P-waves arrive, while a slight increase of the shear stresses is observed. This does not result in yielding of the soil. Next, the $\mathrm{S}$-waves arrive which results in large shear stresses and, consequently, plastic deformation.

\subsection{Experimental validation}

Figure 13 compares the predicted and measured vertical ground vibration velocity. As a reference, results from a linear model which disregards inelastic soil behaviour and slab uplifting are shown as well. In the experimental as well as numerical results, the arrival of different types of waves is observed. This becomes particularly clear in the time history of the vibration velocity at larger distances from the source. The first part of the response is due to fast travelling P-waves while S- and surface waves follow next. The response due to the P-waves is generally characterized by oscillations at smaller time scales than the response due to surface waves. Comparing the results of the non-linear model to the experimental results shows that the wave arrival times are well predicted. The amplitudes of the P-waves are generally overestimated, however, while the amplitudes of the surface waves are underestimated, in particular at larger distances from the source. This is reflected in the frequency domain by overestimation of the experimental results at high frequencies and underestimation at low frequencies and large distances from the source. Additional calculations, not included here, have shown that the underestimation of the response associated with the surface waves may be caused by the overestimation of the material damping ratios of the deep soil layers [22, 23].

Comparing the results of the non-linear and linear models in figure 13 shows that the linear model generally predicts smaller amplitudes for the P-waves than the non-linear model. The most significant difference between both results is found at $5 \mathrm{~m}$ from the source where the non-linear model is clearly much more accurate than the linear model. At larger distances from the soil, the results from both models are reasonably close to each other. This confirms that the discrepancy between the experimental and numerical results at larger distances is mainly due to discrepancies in the prediction of elastic wave propagation. These results suggest that linear models may be used to predict ground vibration at sufficiently large distances from the source, while a non-linear model is needed close to the source to effectively estimate energy dissipation.

\section{Conclusions}

This paper presents a numerical model for the prediction of ground vibration generated by the operation of a pavement breaker. First, a numerical model is developed for the prediction of the impact load due to a single blow of 


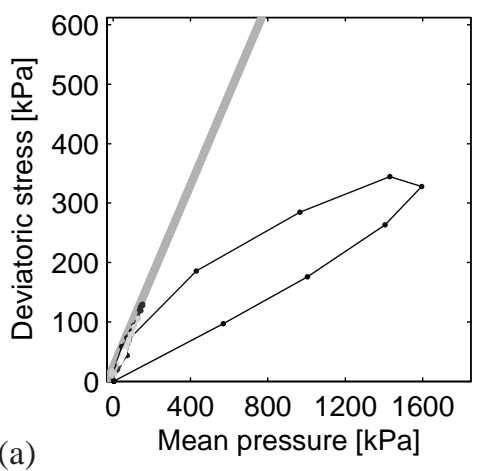

(a)

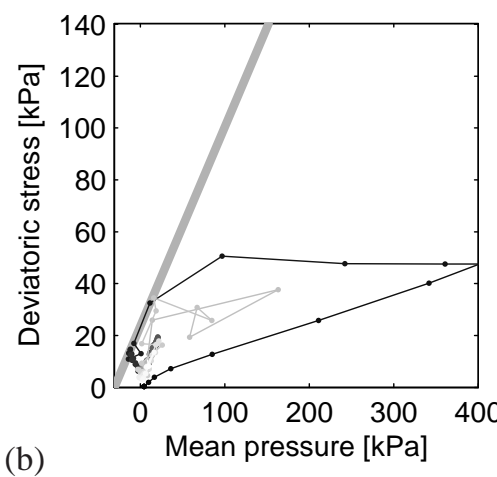

(b)
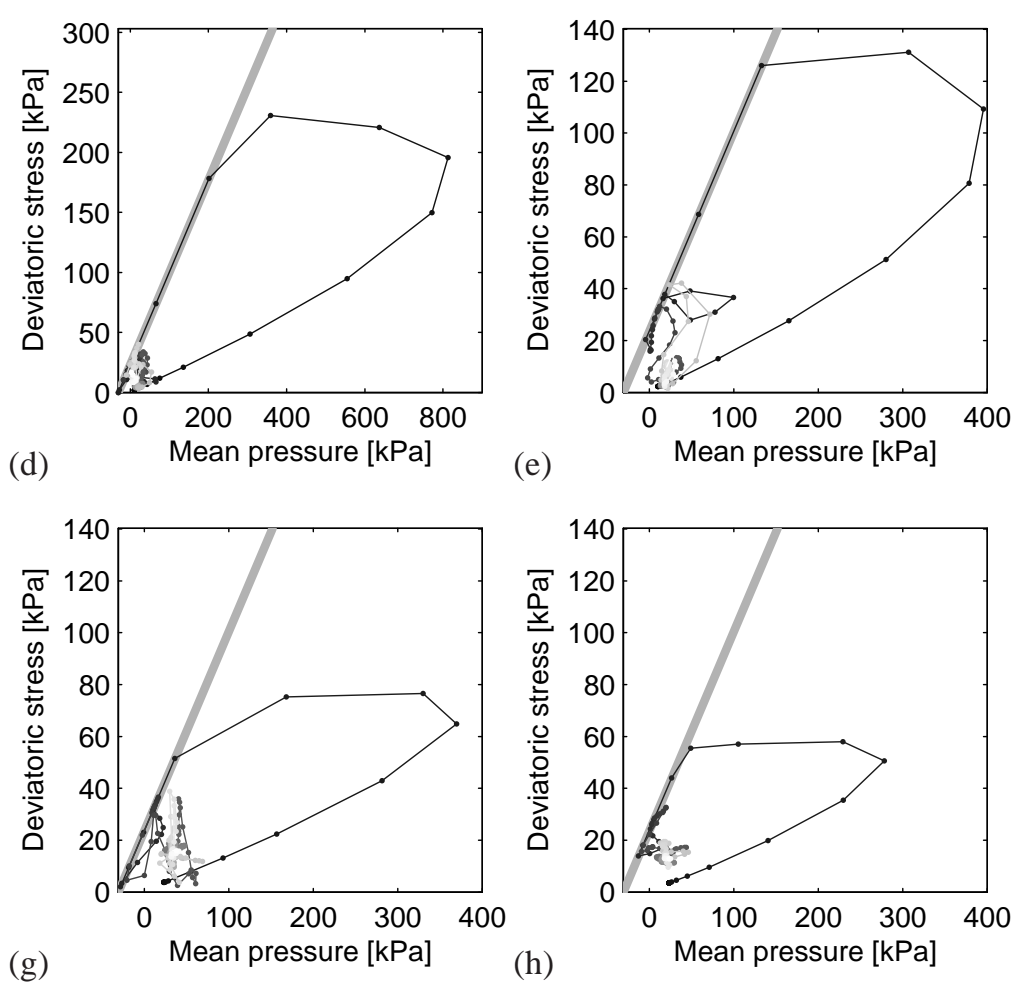

(h)
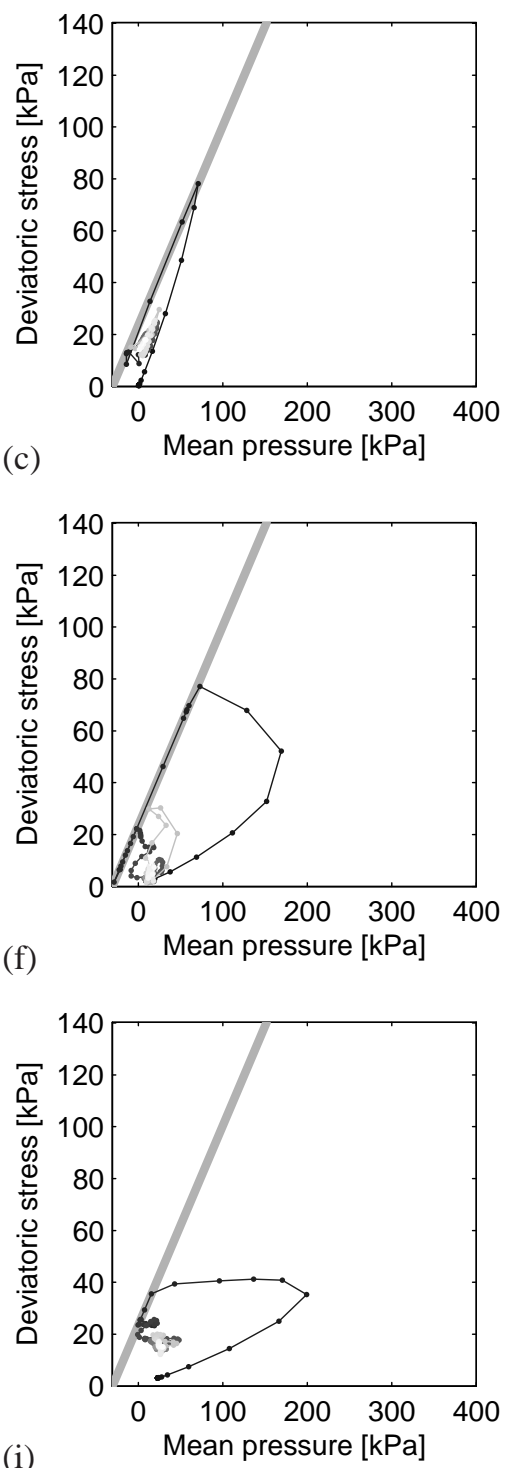

Figure 12: Square root of the second deviatoric stress invariant $\mathrm{I}_{2 \mathrm{~s}}$ versus the mean pressure $\mathrm{I}_{1 \sigma}$ at $(\mathrm{a}) \mathbf{x}=\{0.1 \mathrm{~m}, 0,0\}^{\mathrm{T}},(\mathrm{b}) \mathbf{x}=\{1 \mathrm{~m}, 0,0\}^{\mathrm{T}}$, (c) $\mathbf{x}=\{1.5 \mathrm{~m}, 0,0\}^{\mathrm{T}}$, (d) $\mathbf{x}=\{0.1 \mathrm{~m}, 0,-0.5 \mathrm{~m}\}^{\mathrm{T}}$, (e) $\mathbf{x}=\{1 \mathrm{~m}, 0,-0.5 \mathrm{~m}\}^{\mathrm{T}}$, (f) $\mathbf{x}=\{1.5 \mathrm{~m}, 0,-0.5 \mathrm{~m}\}^{\mathrm{T}},(\mathrm{g}) \mathbf{x}=\{0.1 \mathrm{~m}, 0,-1.5 \mathrm{~m}\}^{\mathrm{T}},(\mathrm{h}) \mathbf{x}=$ $\{1 \mathrm{~m}, 0,-1.5 \mathrm{~m}\}^{\mathrm{T}}$, (i) $\mathbf{x}=\{1.5 \mathrm{~m}, 0,-1.5 \mathrm{~m}\}^{\mathrm{T}}$ due to an impact of the MHB. The stress path is shown from time $t=1.000 \mathrm{~s}$ (black) till $t=1.100 \mathrm{~s}$ (grey). Superimposed is the yield surface (thick grey line).

the pavement breaker. The flexibility of the pavement is accounted for in the calculation by means of a layered elastic halfspace model representing the pavement and the soil. A good agreement is found between the predicted impact force and experimental result obtained from accelerations measured on the drop hammer of a pavement breaker. Second, the load is used to predict ground vibrations generated by the impacts of the pavement breaker. The prediction of ground vibration is performed in two stages. In the first stage, a non-linear time domain FE model that accounts for inelastic soil behaviour and slab uplifting is used to predict the soil response close to the source. In the second stage, the response computed by the FE model along an elastic path in the soil is used to compute response at larger distances from the source. For this purpose, the displacements and tractions along the elastic path are transformed into the frequency domain and introduced in the integral representation theorem. A reasonable agreement is obtained between the results of the nonlinear model and ground vibrations measured during the operation of a MHB. Accounting for 
inelastic soil behaviour and slab uplifting is particularly important for predicting response close to the source. At larger distances, results from the non-linear and linear model considered are fairly similar.

\section{Acknowledgments}

The results presented in this report have been obtained within the frame of the IWT-project VIS-CO 060884, 'Vibration controlled stabilization of concrete slabs for durable asphalt overlaying with crack prevention membrane', funded by IWT Vlaanderen (Institute for the Promotion of Innovation by Science and Technology in Flanders). The authors wish to acknowledge the Belgian Road Research Centre (BRRC) for the collaboration within the frame of this project and the IWT Vlaanderen for its financial support.

The second author is a postdoctoral fellow of the Research Foundation - Flanders (FWO Vlaanderen). The financial support is gratefully acknowledged.

[1] W.H. Ames, W. Chow, A. Sequeira, and R. Johnson, "Survey of earth-borne vibrations due to highway construction and highway traffic," Tech. Rep. CA-DOT-TL-6391-76-20, Office of Transportation Laboratory, California Department of Transportation, Sacramento, California, April 1976.

[2] R. Hendriks, "Transportation related earthborne vibrations (Caltrans experiences)," Tech. Rep. TAV-04-01-R0201, California Department of Transportation, Division of Environmental Analysis, Office of Noise and Hazardous Waste Management, January 2004.

[3] Z. Ozdemir, P. Coulier, M.A. Lak, S. François, G. Lombaert, and G. Degrande, "Numerical evaluation of the dynamic response of pipelines to vibrations induced by the operation of a pavement breaker," Soil Dynamics and Earthquake Engineering, vol. 44, pp. 153-167, 2013.

[4] A.J. Deeks and M.F. Randolph, "Analytical modeling of hammer impact for pile driving," International Journal for Numerical and Analytical Methods in Geomechanics, vol. 17, pp. 279-302, 1993.

[5] J.M. Roësset, E. Kausel, V. Cuellar, J.L. Monte, and J. Valerio, "Impact of weight falling onto the ground," Journal of Geotechnical Engineering, Proceedings of the ASCE, vol. 120, no. 8, pp. 1394-1412, 1994.

[6] S. Thilakasiri, G. Mullins, P. Stinnette, and M. Gunaratne, "Impact of weight falling onto the ground - Discussion," Journal of Geotechnical Engineering, Proceedings of the ASCE, vol. 122, no. 5, pp. 415-416, 1996.

[7] M.R. Svinkin, "Impact of weight falling onto the ground," Journal of Geotechnical Engineering, Proceedings of the ASCE, vol. 122, no. 5, pp. 414-415, 1996.

[8] A.G. Chehab and M.H. El Naggar, "Response of block foundations to impact loads," Journal of Sound and Vibration, vol. 276, pp. 293-310, 2004.

[9] G.N. Bycroft, "Impact of a rigid body on an elastic half space," Journal of Applied Mechanics, Transactions of the ASME, vol. 44, no. 2, pp. 227-230, 1977.

[10] Y.K. Chow, D.M. Yong, K.Y. Yong, and S.L. Lee, "Monitoring of dynamic compaction by deceleration measurements," Computers and Geotechnics, vol. 10, no. 3, pp. 189-209, 1990.

[11] M.A. Lak, G. Lombaert, H. Verbraken, and G. Degrande, "Vibration measurements during the operation of a multi-head breaker on a concrete road at a site in Waarschoot," Tech. Rep. BWM-2009-14, Department of Civil Engineering, KU Leuven, August 2009.

[12] J.P. Wolf, Soil-structure-interaction analysis in the time domain, Prentice-Hall, Englewood Cliffs, New Jersey, 1988.

[13] J.L. Humar, Dynamics of structures, Taylor \& Francis, 2002.

[14] D. Clouteau and D. Aubry, "Computational soil-structure interaction," in Boundary Element Methods for Soil-Structure Interaction, W.S. Hall and G. Oliveto, Eds., pp. 61-125. Kluwer Academic Publishers, 2003.

[15] C.J. Martins, J.A.M. Carrer, W.J. Mansur, and F.C. Araújo, “On the use of pseudo-forces to consider initial conditions in 3D time- and frequency-domain acoustic analysis," Computer Methods in Applied Mechanics and Engineering, vol. 195, pp. 4371-4382, 2006.

[16] E. Kausel and J.M. Roësset, "Stiffness matrices for layered soils," Bulletin of the Seismological Society of America, vol. 71, no. 6, pp. 1743-1761, 1981.

[17] E. Kausel, Fundamental solutions in elastodynamics: a compendium, Cambridge University Press, New York, 2006.

[18] M. Schevenels, S. François, and G. Degrande, "EDT: An ElastoDynamics Toolbox for MATLAB," Computers \& Geosciences, vol. 35, no. 8, pp. 1752-1754, 2009

[19] BRRC, "Beproevingsverslag P.V.CO 8288-3/1540, Lovendegem N9," 2008.

[20] European Committee for Standardization, ENV1992-1-1:1991 Eurocode 2: Design of concrete structures - Part 1-1: General rules and rules for buildings, 1991.

[21] S.A. Badsar, M. Schevenels, M.A. Lak, and G. Degrande, "Determination of the dynamic soil properties with the seismic refraction method and the SASW method at a site in Waarschoot," Tech. Rep. BWM-2009-17, Department of Civil Engineering, KU Leuven, August 2009.

[22] M.A. Lak, S. François, M. Schevenels, G. Degrande, and G. Lombaert, "Prediction of ground vibrations generated by a falling-weight pavement breaker," Report BWM-2012-06, Department of Civil Engineering, KU Leuven, July 2012, IWT-Project VIS-CO 060884.

[23] M.A. Lak, Numerical prediction of ground vibrations generated by road traffic and pavement breaking, Ph.D. thesis, Department of Civil Engineering, KU Leuven, 2013.

[24] M.D. Bolton and J.M.R. Wilson, "Soil stiffness and damping," in 1st European Conference on Structural Dynamics (EUROPEAN 90), Kratzig, W.B. et al., Ed., Bochum, Germany, 1991, pp. 209-216.

[25] R.L. Kuhlemeyer and J. Lysmer, "Finite element method accuracy for wave propagation problems," Journal of the Soil Mechanics and Foundation Division, Proceedings of the ASCE, vol. 99, no. SM5, pp. 421-427, 1973.

[26] V.J. Marks and C. Anderson, "Crack and seat PCC pavement prior to resurfacing, US 59 - Shelby county," Final Report Project HR-527, Iowa Department of Transportation, Highway division, Office of materials, 1993.

[27] Comité Euro-International du Béton, CEB-FIP Model Code, 1998. 
[28] D.E. Lambert and C.A. Ross, "Strain rate effects on dynamic fracture and strength," International Journal of Impact Engineering, vol. 24, pp. 985-998, 2000.

[29] J. Lysmer and R.L. Kuhlemeyer, "Finite dynamic model for infinite media," Journal of the Engineering Mechanics Division, Proceedings of the ASCE, vol. 95, no. EM4, pp. 859-877, 1969.

[30] A. Niemunis. Extended hypoplastic models for soils. PhD thesis, Ruhr Universität Bochum, Germany, 2003.

[31] P-A von Wolffersdorff. A hypoplastic relation for granular materials with a predefined limit state surface. Mechanics of Cohesive-frictional Materials, 1(3):251-271, 1996.

[32] J.P. Bardet. Bounding surface plasticity model for sands. ASCE Journal of Engineering Mechanics, 112(11):1198-1217, 1986.

[33] J.C. Simo and T.A. Laursen, "An augmented Lagrangian treatment of contact problems involving friction," Computers and Structures, vol. 42, no. 1, pp. 97-116, 1992.

[34] ANSYS Inc., Contact Technology Guide, ANSYS Release 11.0, January 2007. 

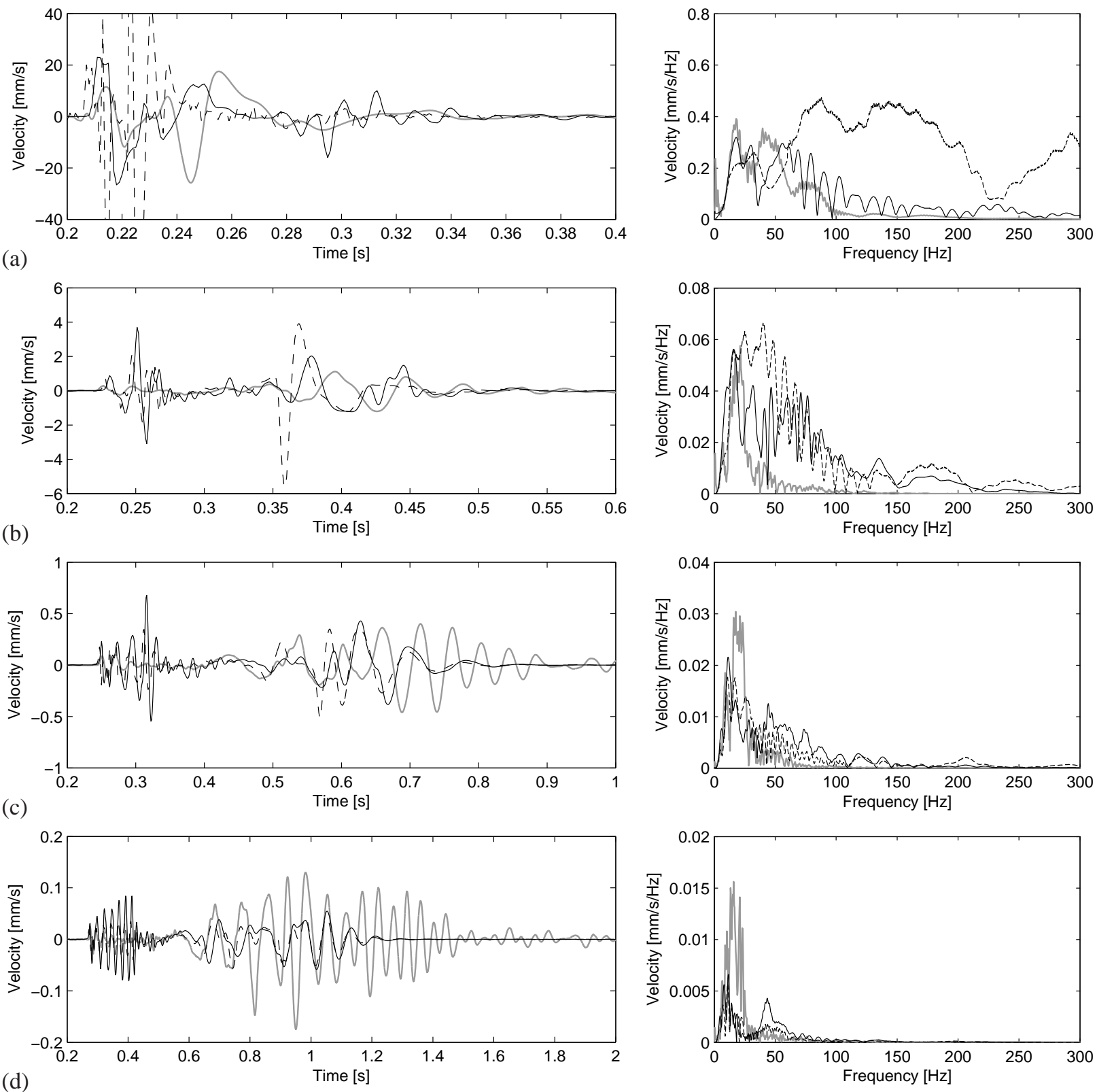

Figure 13: Time history (left) and narrow band frequency spectrum (right) of the vertical vibration velocity at (a) $5 \mathrm{~m}$, (b) $25 \mathrm{~m}$, (c) $57 \mathrm{~m}$, and (d) $105 \mathrm{~m}$ from the road due to an impact of the MHB predicted with the non-linear (solid black line) and linear (dashed black line) model compared with the experimental results (grey line). 